\title{
The disentangling of hysteretic spin transition, polymorphism and metastability in bistable thin films formed by sublimation of bis(scorpionate) Fe(II) molecules
}

\author{
O. Iasco, ${ }^{a}$ M.-L. Boillot, ${ }^{a *}$ A. Bellec, ${ }^{b}$ R. Guillot, ${ }^{a}$ E. Rivière, ${ }^{a}$ S. Mazerat, ${ }^{a}$ \\ S. Nowak, ${ }^{c}$ D. Morineau, ${ }^{d}$ A. Brosseau, ${ }^{e}$ F. Miserque, ${ }^{f}$ V. Repain ${ }^{b}$ and T. Mallah ${ }^{a^{*}}$
}

\author{
${ }^{*}$ Corresponding authors \\ a - Institut de Chimie Moléculaire et des Matériaux d'Orsay, Univ Paris Sud, Université Paris-Saclay, CNRS, UMR 8182 , \\ 91405 Orsay Cedex, France E-mail: marie-laure.boillot@u-psud.fr \\ b - Laboratoire Matériaux et Phénomènes Quantiques, Univ Paris Diderot, Sorbonne Paris Cité, CNRS, F-75205 Paris \\ Cedex, France \\ C - Plateforme RX, UFR de Chimie, Univ Paris Diderot, Sorbonne Paris Cité, 35 rue Hélène Brion, F-75205 Paris Cedex 13, \\ France \\ d - Institut de Physique de Rennes, CNRS, Université de Rennes I, UMR 6251, F-35042 Rennes, France \\ e - ENS Paris-Saclay, PPSM, CNRS, UMR 8531, France \\ $\mathrm{f}$ - DEN/SCCME/CEA, Université Paris-Saclay, France
}

We investigate the sizeB dependent bistability of a $\mathrm{Fe} "\left[\mathrm{HB}\left(3,5 \mathrm{~B}(\mathrm{Me})_{2} \mathrm{Pz}\right)_{3}\right]_{2}$ spinB transition compound in the form of thin films, the thickness of which varies from 130 to $8500 \mathrm{~nm}$. From combined structural, magnetic and optical measurements, we demonstrate that the materials prepared by sublimation consist in crystalline grains of the triclinic phase exhibiting the firstB order spin transition coexisting with those of a new highB spin metastable tetragonal polymorph in a quite large proportion (ca. 42\%). Accordingly, we show that the asB sublimed thin B film of a $130 \mathrm{~nm}$ thickness retains a remarkable $17 \mathrm{~K}$ width hysteresis $\left(T_{1 / 2}=152 \mathrm{~K}\right.$ ) while the spin transition becomes quantitative by the thermal annealing of the metastable phase at $373 \mathrm{~K}$. Consistently with the calorimetric data, the structural analysis based on singleB crystal xB ray diffraction measurements provides evidences for a thermal hysteresis resulting from successive crystallographic phase transitions, which account for the asymmetric shape of hysteresis and the variation of cooperativity observed in the magnetic and optical data and that, whatever the material dimension.

\section{Introduction}

In parallel to the development of advanced functional materials, the control of their physical properties at the nanoscale has become a major issue in materials science and engineering. ${ }^{1}$ The size-dependent effects that are essentially governed by the interface and the structure of nanoobjects, manifest themselves on the stability, the reactivity and the collective behavior. This issue is presently investigated with bistable spin-crossover ${ }^{2}$ (SCO) nanomaterials. ${ }^{3,4}$ The SCO materials reversibly switch in response to external stimuli (temperature, pressure, light, electric field, ...). The low-spin (LS, $\mathrm{S}=0$ for Fe") to high-spin (HS, $\mathrm{S}=2$ ) crossover, that occurs at the molecular level via the change of occupancy of $d_{s}$ antibonding orbitals, results in the swelling of HS molecules promoting elastic cooperative interactions through the solid and hysteretic transformation, i.e. bistability.

The relationship between size and cooperativity was mainly investigated on SCO nanoparticles of coordination networks. The general trends observed by increasing their surface/volume ratio ${ }^{5,6,7}$ are the loss of hysteresis due to the decrease of cooperativity, the downshift of the transition temperature and the incompleteness of the spin-state switching. Among other things, these effects derive from the nanoparticle surface (energies, strains) ${ }^{8,9,10}$ and thus from their interfaces with the external environment. It has been established that the stabilization of HS (LS) residue with a down- (up-)shift of transition temperature $\left(T_{1 / 2}\right)$ may be accounted for by the negative (positive) value of the difference between the HS and LS surface energy. ${ }^{10}$ The lattice dynamic is currently considered in relation with the partial restoration of the hysteresis observed in the case of ultra-small nanoparticles. ${ }^{11}$ The fact that well-defined but aggregated particles without any coating present a hysteresis identical ${ }^{8}$ and even larger ${ }^{12}$ than the bulk, was assigned to the interparticle coupling and to better crystallinity respectively. The friction between surfaces may account for the spreading of the hysteresis of a single nanocrystal in contact with a substrate. ${ }^{13}$ So, it emerges from the quite numerous studies, that the combination of size, crystallinity, surface and environment effects influences in a non-trivial manner the cooperativity and the bistability of SCO nanoparticles.

The effect of dimension on the physical properties of SCO materials was also investigated on thin films of coordination networks and on molecule-based materials. ${ }^{14-24}$ Bousseksou et al. elaborated ultra-thin films of the 3D Hofmann clathrates that retain a bistability close to room temperature (RT) using the sequential assembly approach in solution. ${ }^{14}$ For the wet processing, the molecule-based materials suffer from some drawbacks as their SCO features derive from the packing of molecules via supramolecular forces. However the sublimation may be a valuable approach if the molecules present adequate physicochemical properties. ${ }^{15-24}$ Beaurepaire et al. first reported a gradual SCO of films based on $\mathrm{Fe}(\text { phen })_{2}(\mathrm{NCS})_{2}$ (phen $=$ phenanthroline), while bulk presents an abrupt spin transition. ${ }^{16 a}$ Then they considered the case of $570 \mathrm{~nm}$-thick film of the bistable $\mathrm{Fe}\left[\mathrm{HB}\left(3,5-(\mathrm{Me})_{2} \mathrm{Pz}\right)_{3}\right]_{2}$ material ${ }^{20}$ $(\mathrm{Pz}=$ pyrazolyl) that retains an asymmetrical hysteresis (at $\sim 150$ $\mathrm{K}$, of $\sim 21 \mathrm{~K}$ width). They also suggested a metastable structural organization in the as-sublimed films.

In order to address the issue of the size reduction effect as it was done for nanoparticles, we focused on the behavior of much more thinner films (i.e. $90-130 \mathrm{~nm}$ ) that are relevant to technological use if they showed bistability.

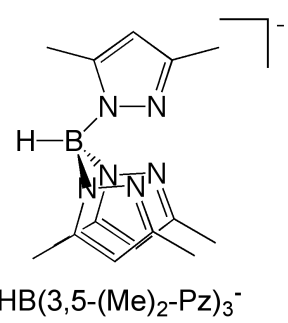

Scheme of the anionic ligand 
To the best of our knowledge, a unique example ${ }^{24}$ has been reported so far. ${ }^{14-24}$ It consists of a film having a thickness smaller than $150 \mathrm{~nm}$ (case of $\mathrm{Fe}\left[\mathrm{HB}(\mathrm{tz})_{3}\right]_{2}$ with tz=triazolyl, process spreading over ca. $60 \mathrm{~K}$, hysteresis width $<1 \mathrm{~K}$ ).

It is worth noting that one (or two) monolayer and isolated molecules of SCO molecular systems have been also described but to date, no thermal hysteresis was observed. In one case, some of us demonstrated the collective transformation of a 2D crystal of $\mathrm{Fe}\left[\mathrm{HB}\left(3,5-(\mathrm{Me})_{2} \mathrm{Pz}\right)_{3}\right]_{2}$ on a gold surface, based on the light-induced excited spin-state trapping (LIESST) process, ${ }^{25}$ using scanning tunneling microscopy. ${ }^{26}$ Memory effects in the conductance or transport properties are presently searched for with electronic devices based on SCO films, ${ }^{24}$ nanostructures, single nanoparticles ${ }^{27}$ or molecules ${ }^{28}$.

The SCO properties of the pseudo-octahedral $\mathrm{Fe}[\mathrm{HB}(3,5-$ $\left.\left.(\mathrm{Me})_{2} \mathrm{Pz}\right)_{3}\right]_{2}$ compound were first reported by Jesson et al., ${ }^{29}$ but apart from the crystal structure that was solved at $289 \mathrm{~K},{ }^{30}$ the structural and thermodynamical properties of the bulk material are unknown. Therefore, we first report the analysis of the first-order spin transition based on single-crystal x-ray diffraction and differential scanning calorimetry (DSC) measurements. Then we describe the preparation of films of $\mathrm{Fe}\left[\mathrm{HB}\left(3,5-(\mathrm{Me})_{2} \mathrm{Pz}\right)_{3}\right]_{2}$, their full characterization by complementary techniques, such as Atomic Force Microscopy (AFM), X-ray Photoelectron Spectroscopy (XPS), x-ray diffraction (XRD), magnetism and spectrometry in the infrared and UV-visible regions, and the study of their bistability properties.

We demonstrate that the sublimation process highly impacts the structural properties of the compound and thus the magnetic behavior of the films. Several phases are formed including a metastable one, similar to the bulk one, that is spin-crossover inactive. We also demonstrate that hysteresis persists in a $130 \mathrm{~nm}$ film and probably of lower thickness but we selected that one as it nicely suited for an analysis by variable-temperature optical measurements.

\section{Results}

The compound was first studied in the form of bulk material (polycrystalline powder and single-crystals) and then in the form of thin layers obtained by physical vapor deposition on various substrates.

\section{Hysteretic behaviour of the bulk material}

Calorimetric, magnetic and x-ray diffraction measurements of powder. The DSC curves (Fig. S1) of the polycrystalline powder were recorded between 373 and $113 \mathrm{~K}$ at a sweep rate of 10 $\mathrm{Kmin}^{-1}$. The plot shows beside a tiny peak close to room temperature, three successive peaks corresponding to the total enthalpy variation (total integration, $\Delta \mathrm{H}_{\text {tot }}=10.2 \mathrm{kJmol}^{-1}$ ) in the SCO range. They are well resolved in the cooling mode but show disparities of widths and intensities. A reproducible evolution of the material appears upon the second thermal cycle as the intermediate component in the cooling branch vanishes to the benefit of the lowest temperature one but the total peak integration remains quasi unchanged. No significant modification appears in the subsequent cycle performed at a sweep rate of $1 \mathrm{Kmin}^{-1}$. An estimate of the entropy value ( $\Delta \mathrm{S}$ $=\Delta H / T_{1 / 2}$ with $T_{1 / 2}$ extracted from the magnetic data (Fig. 1), $\mathrm{T}_{1 / 2}=(\mathrm{T} \downarrow+\mathrm{T} \uparrow) / 2$ with $\mathrm{T} \downarrow=174 \mathrm{~K}, \mathrm{~T} \uparrow=205 \mathrm{~K}$ in cycle 1$)$ is ca. $53.8 \mathrm{JK}^{-1} \mathrm{~mol}^{-1}$. The $\Delta \mathrm{H}$ and $\Delta \mathrm{S}$ thermodynamical parameters are within the range expected for $\mathrm{Fe}^{\text {" }}$ compounds exhibiting a spin transition. ${ }^{2,31}$

The magnetic measurements of this powdered sample recorded before and after the $400 \mathrm{~K}$ in-situ heating show consistent features. The as-synthesized and the annealed material in form of powder exhibit complete first-order spin transitions with minor differences in their characteristics.

At room temperature, the polycrystalline powder presents a $x$ ray diffractogram (Fig. S2 and S3) corresponding to the one calculated from the single-crystal x-ray diffraction data (see below). Moreover, the powder annealing at $373 \mathrm{~K}$ improves the powder crystallinity (as seen for instance with a $5 \%$ reduction of the full width at half maximum (FWHM) of the (001) reflection). So the thermal evolution of the assynthesized powder that slightly modify the hysteresis loop may be compared to the run-in ${ }^{24}$ effect sometimes reported with bistable SCO materials even in absence of solvent traces.

Single-crystal $x$-ray diffraction measurements. After several attempts, we succeeded in finding a single-crystal of $\mathrm{Fe}\left[\mathrm{HB}\left(3,5-(\mathrm{Me})_{2} \mathrm{Pz}\right)_{3}\right]_{2}$ that does not shatter upon cooling below $220 \mathrm{~K}$ (Fig. S4). The structural analysis was performed by collecting first $\mathrm{x}$-ray data in the unknown LS phase $(100 \mathrm{~K})$, then at $240 \mathrm{~K}$ after the gradual SCO. The data at $298 \mathrm{~K}$ were collected on another fresh single crystal.

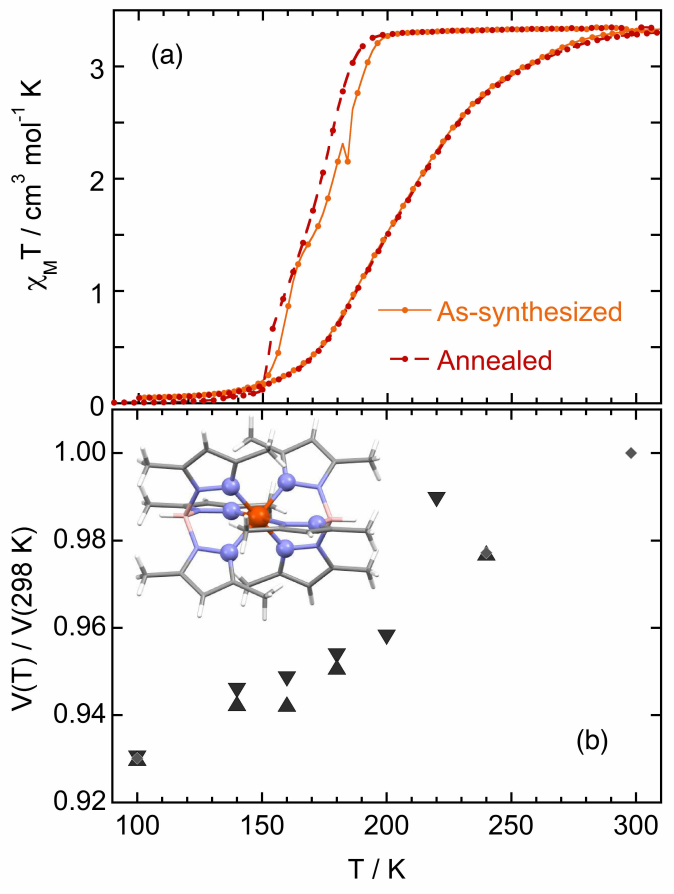

Fig. 1 (a) Temperature dependence of $\chi_{M}{ }^{\top}\left(\chi_{M}=\right.$ molar magnetic susceptibility, scanning rate $=2 \mathrm{Kmin}^{-1}$ ) for the as-synthesized and the in-situ annealed powder; (b) Molecular structure of $\mathrm{Fe}\left[\mathrm{HB}\left(3,5-(\mathrm{Me})_{2} \mathrm{Pz}\right)_{3}\right]_{2}$ at $100 \mathrm{~K}$ and plot of the relative value of the unit-cell volume as a function of temperature in the cooling $(\boldsymbol{\nabla})$ and heating mode $(\mathbf{\Delta})$ as well as values corresponding to the single-crystal $x$-ray structures $(\diamond)$. 
The compound, isolated as colorless needles, crystallizes in the triclinic $P$-1 space group (see the footnote ${ }^{\S}$ and Table ST1). The crystalline structure studied at three different temperatures (100, 240 and $298 \mathrm{~K}$ ) show no change in the space group. The asymmetric unit contains one half of complex with the $\mathrm{Fe}^{\text {"I }}$ ion lying on an inversion center. In Fig. 1, the $\mathrm{Fe}^{\text {II }}$ chelation by two $\mathrm{HB}\left(3,5-(\mathrm{Me})_{2} \mathrm{Pz}\right)_{3}$ anions forms a $\left[\mathrm{FeN}_{6}\right]$ core with a pseudo three-fold symmetry axis along the two $B$ atoms (ORTEP view in Fig. S5). An evolution in the average $\mathrm{Fe}-\mathrm{N}$ bond length is observed (Fe-N = 1.995 (100 K), 2.140 (240 K) and $2.178 \AA$ (298 $\mathrm{K})$ ) indicating the molecular expansion typical for the LS to HS crossover, as shown by magnetic measurements. The $240 \mathrm{~K}$ value ( $79 \%$ of the maximal Fe- $\mathrm{N}$ change) in the ascending branch of the hysteresis loop corresponds to an almost complete conversion (in Fig. 1, HS fraction $=0.82$ for $\chi_{\mathrm{M}} \mathrm{T}^{\mathrm{HS}}=$ $\left.3.37 \mathrm{~cm}^{3} \mathrm{~mol}^{-1} \mathrm{~K}\right)$. The distortion indices $(\Sigma, \theta$ parameters and Fe- $\mathrm{N}_{\mathrm{i}}-\mathrm{N}_{\mathrm{j}}-\mathrm{X}, \mathrm{X}=\mathrm{C}$ or $\mathrm{B}$ torsion angles) that are useful to quantify the deviation of molecular geometry from the idealized $\mathrm{O}_{\mathrm{h}}$ and $\mathrm{C}_{3 v}$ symmetries are displayed in Table ST2. The LS complex adopts the regular geometry close to the octahedral symmetry $\left(\Sigma=2.4^{\circ}, \theta=5^{\circ}\right)$ while the HS one is much more distorted $(\Sigma=$ $\left.39.9^{\circ}, \theta=54^{\circ}\right)$. Moreover, the values of pyrazolyl twists (average angles: $\mathrm{Fe}-\mathrm{N}_{\mathrm{i}}-\mathrm{N}_{\mathrm{j}}-\mathrm{C}_{\mathrm{k}}=178.5(174.2)^{\circ}, \mathrm{Fe}-\mathrm{N}_{\mathrm{i}}-\mathrm{N}_{\mathrm{j}}-\mathrm{B}=$ $1.4(6.5)^{\circ}$ at $100(298) \mathrm{K}$ ) fall within the ranges of angles tabulated for LS and HS forms of these spin-crossover complexes. $^{32}$

The neutral complexes are densely packed in the crystal. At $100 \mathrm{~K}$, the structure cohesion is reinforced along $a$ axis and also in the (010) plane via van der Waals interactions involving $\mathrm{Me}, \mathrm{C}$ (or HC) groups of two (or three) pyrazolyl rings (see details in ESI, Fig. S6) belonging to neighboring complexes. The shortest intermetallic distances, observed in the (010) plane, change from Fe---Fe $=8.724$ and $10.821 \AA$ at $100 \mathrm{~K}$ to 8.777 and $10.992 \AA$ at $240 \mathrm{~K}$ and then, to 8.812 and $10.767 \AA$ at 298 $\mathrm{K}$, as a consequence of the thermal SCO and the large anisotropic lattice deformation $(\Delta \mathrm{V} / \mathrm{V}=[\mathrm{V}(100 \mathrm{~K})-\mathrm{V}(298$ $\mathrm{K})] / \mathrm{V}(298 \mathrm{~K}) \sim 7 \%)$.

The plot of unit-cell parameters vs. temperature is especially informative (Fig. 1 and S7). Upon cooling, one observes above $200 \mathrm{~K}$, discontinuities of angles indicating the occurrence of crystallographic phase transitions preceding the SCO process. Signatures of subsequent phase transitions coupled to SCO, appear at $c a .140 \mathrm{~K}$ ( $a$ parameter) then upon heating between 180 and $240 \mathrm{~K}$ ( $\alpha$ and $\beta$ angles) and finally above $240 \mathrm{~K}$ ( $\alpha$ and $\beta$ angles). This non-monotonous transformation of $\mathrm{Fe} " \mathrm{HB}(3,5-$ $\left.\left.(\mathrm{Me})_{2} \mathrm{Pz}\right)_{3}\right]_{2}$ is reminiscent of structural instabilities pointed by Reger et al. with similar complexes. ${ }^{33}$

The $2 \%$ change of volume between 200 and $140 \mathrm{~K}$, that is associated to the SCO and the solid contraction, corresponds to the values expected for an abrupt HS to LS transition of Fe" ion. The thermal hysteresis derives from successive crystallographic phase transitions, which are partly coupled to the electronic switching. The asymmetric shape of hysteresis and the drastic changes of cooperativity can be accounted for by distinct structural reorganizations taking place in the cooling and heating mode prior the SCO.

\section{Characterization of as-sublimed films}

Layers of different thicknesses were prepared by varying the base pressure and the sublimation temperatures $\left(T_{S}=125\right.$ and $120-140{ }^{\circ} \mathrm{C}$ in secondary vacuum and an ultra-high vacuum chamber, respectively) without any notable effect on the grown layer characteristics.

Spectroscopic and surface techniques were used to probe the chemical nature of the deposits. The well-resolved IR spectra of films exclusively present the peaks characterizing the molecule in the bulk (Fig. S8). The XPS spectra (Fig. S9) were recorded at the Fe-2p, N-1s and C-1s edges for a $130 \mathrm{~nm}$-thick sample. The $\mathrm{Fe} / \mathrm{N}$ atomic ratio was estimated using the $\mathrm{Fe}-$ $2 p_{3 / 2}$ and $\mathrm{N}-1 \mathrm{~s}$ core level areas corrected by the Scofield sensitivity factors and the spectrometer transmission function. The Shirley algorithm has been used for the background subtraction. ${ }^{34,35}$ We find an atomic $\mathrm{Fe} / \mathrm{N}$ ratio of $7 / 93$ (1/13) very close to the theoretical value $(1 / 12)$. The two survey spectra, recorded at the beginning and the end of the study, are identical showing that no detectable damage has occurred. This study demonstrates the chemical integrity of the molecules after the evaporation process for the sensed thickness that probably does not exceed $10 \mathrm{~nm}$; it is in line with the other spectroscopic studies that sense the whole film thickness.

The layer thicknesses (from 90 to $8460 \mathrm{~nm}$ ) were determined by profilometry (Table ST3). The AFM topographic images (Fig. S10) show the textured and extended coverages of the substrates formed by grains of matter. As an example, the 130 $\mathrm{nm}$-thick films consist in two populations of nanograins whose sizes average around $110(30)$ and $230(60) \mathrm{nm}$. From the dataset in Table ST3, it also appears that the larger the layer thickness is, the larger the RMS roughness and the larger the grains are (for instance RMS $=20 \mathrm{~nm}$ and $>90 \mathrm{~nm}$ for 130 (13) $\mathrm{nm}$ - and 8020 (300) nm-thick layer, respectively). Parallel to the growth of the film thickness, the grain sizes increase (values possibly larger than $1 \mu \mathrm{m}$ for the thickest films).

For the sake of simplicity, we chose to describe below the properties of two representative samples whose thicknesses are at the boundaries of the explored domain (the $130 \mathrm{~nm}$ and the $8020 \mathrm{~nm}$-thick films, being noted $\mathbf{1}$ and $\mathbf{2}$ respectively). The consistent data characterizing the other films are displayed in the supplementary material.

\section{Structural studies of the polycrystalline films}

The solid-state properties that depend on the crystallinity and the arrangements of grains, were probed by x-ray diffraction. The XRPD diagram of 1 recorded in the grazing incidence mode on a standard apparatus was found to be the same as reported $^{20}$ (essentially a large peak around $2 \theta=9.99^{\circ}$ ). However, using a set-up with higher resolution, two well resolved peaks (Fig. S11) were observed that allow a better analysis of the structural data. In the following, we will focus on 2 because of the larger intensity of the diffraction peaks. In Fig. 2, one can see for the as-sublimed film 2 the intense Bragg peak at $2 \theta=9.98^{\circ}$ that is absent in the crystallographically characterized phase (hereafter noted bulk phase) unlike the 
peak at $10.20^{\circ}(100)$ or other minute signals. Conversely, the (01-1) reflection at $10.06^{\circ}$ and the relative intensities of the (001), (010) and (100) reflections are not reproduced in the film pattern. These differences may result from a polymorphic modification and a texture effect. ${ }^{20,36}$ After the film annealing (one hour at $100{ }^{\circ} \mathrm{C}$ ), the new patterns (Fig. 2 and S11) evidence the irreversible transformation of a metastable state.

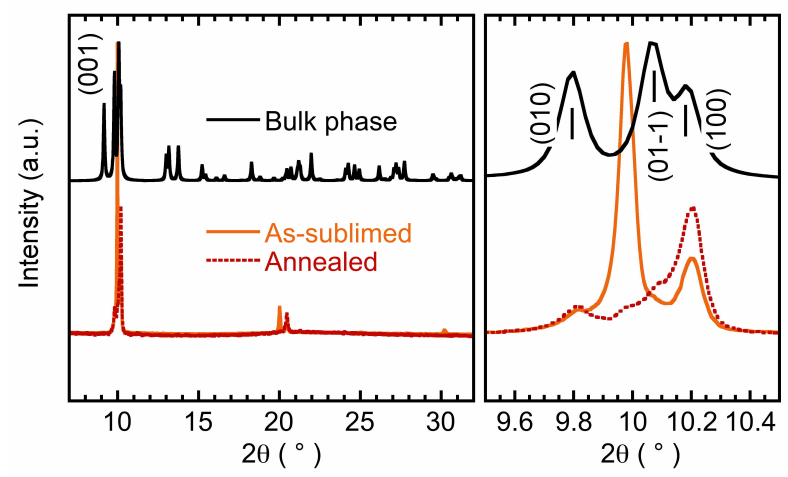

Fig. 2. X-ray diffractograms of $\mathbf{2}$ (the $8020 \mathrm{~nm}$-thick layer) at $298 \mathrm{~K}$ before (orange) and after (red) the irreversible phase transformation induced by annealing at $100{ }^{\circ} \mathrm{C}$. In black is shown the pattern calculated from the $298 \mathrm{~K}$ single-crystal x-ray structure and on the right, the patterns expansion between 9.5 and $10.5^{\circ}$.

The phase transition followed by XRD (Fig. S12) appears between 76 and $100^{\circ} \mathrm{C}$. It results in the disappearance of the $9.96^{\circ}$ extra peak and the reinforcement of others, which lead to the resolution of the signal around $10.1^{\circ}$. This behavior is indicative of a coexistence of phases: a metastable one ascribed to the $9.98^{\circ}$ Bragg peak and the bulk phase with a preferential orientation of crystals along with the [100] direction.

To get some insight on the nature of the sublimed matter, we examined the mixture of needle- and platelet-like crystals (Fig. S13) removed by rinsing the substrate with a nonsolvent $\left(\mathrm{Et}_{2} \mathrm{O}\right)$. From a micrometric-sized platelet, we characterized a new polymorph, ${ }^{\S \S}$ that crystallizes in a tetragonal crystal system with a $P-42, m$ space group (see in ESI, Table ST1, Fig. $\mathrm{S} 13)$. This phase compares the one identified for a pyrazolylborate analogue $^{36}$ also prepared by sublimation ( $P 4_{2} \mathrm{ncm}$ space group). Unfortunately, our poor diffraction data prevent a discussion of structural details, as for instance the metal-ligand distances and the origin of residual electronic density in channels of sub-nanometric size, but the unit-cell volume is ca. $5 \%$ larger (the solvent contribution being omitted) than that of the triclinic polymorph. It can be noted, that in absence of wetting and irrespectively to the air exposition, the as-sublimed layers retain their crystalline character over several months.

According to this study, two polymorphs -a tetragonal and a triclinic one- coexist in the as-sublimed samples and the metastable tetragonal phase disappears by annealing to form films of the pure and stable triclinic phase with the [100] orientation.

\section{Magnetic and optical investigations of films}

The spin-crossover characteristics were first determined with direct magnetic measurements of the thickest films.

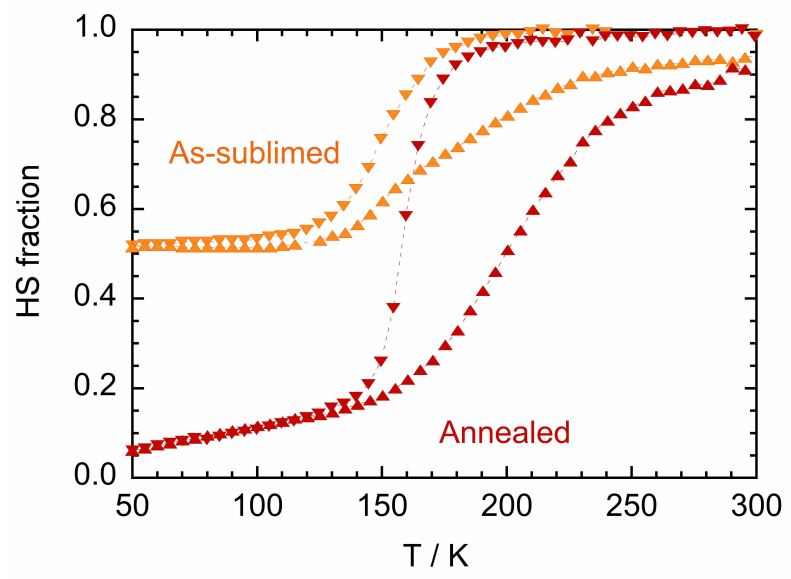

Fig. 3 HS fraction vs. T curve determined from magnetic measurements of $\mathbf{2}$ in the assublimed $(\boldsymbol{\nabla}, \mathbf{\Delta})$ and the annealed $(\boldsymbol{\nabla}, \mathbf{\Delta})$ form (scanning rate $\left.=1.6 \mathrm{Kmin}^{-1}\right)$.

The study was extended to the thinner samples by using the higher sensitivity of the electronic absorption spectra in the UV-vis region. The influence of the phase transition on the switching behavior was probed either after an in-situ (combined optical and magnetic studies) or after ex-situ (optical study) annealing.

Magnetization measurements. The magnetization of the assublimed films (thicknesses, from 2660 to $8460 \mathrm{~nm}$ ) was measured between 300 and $50 \mathrm{~K}$. The HS fraction vs. T curves were extracted from these data by assuming a HS fraction equal to 1 at $300 \mathrm{~K}$ (see below the UV-vis spectra). The representative plot (Fig. 3) confirms the occurrence of a spintransition associated to an asymmetrical hysteresis but also reveals a quite large fraction of SCO inactive species. The latter disappears after the in-situ annealing as we observe the almost complete first-order spin transition that is typical for the bulk triclinic polymorph. The annealing induces the broadening of the hysteresis and an upshift of the transition temperature (> $10 \mathrm{~K})$. However instabilities due to the signal weakness at $\sim R T$ (or sample configuration) did not always allow reliably determining the ascending branch of hysteresis.

The proportion of HS residue ( $\mathrm{x}^{\mathrm{HS}}$ res) was precisely quantified by analyzing the magnetization $v s$ the magnetic field data at low-temperature (in the as-sublimed films: $39 \leq x^{\text {HS }}{ }_{\text {res }} \leq 48 \%$; after annealing: $\mathrm{x}^{\mathrm{HS}}$ res $\left.\leq 5 \%\right) .{ }^{37}$

The preservation of the characteristics of the first-order spin transition is consistent with the crystalline character of the samples that is enhanced by annealing (Fig. S12).

Optical measurements. To further investigate the sizedependent properties of the layers, we have collected their UV-vis absorption spectra as a function of temperature. Fig. 4 shows the typical spectra of the as-sublimed $130 \mathrm{~nm}$-thick layer (1) (other data in Fig. S14). At $325 \mathrm{~K}$, the spectrum is essentially featureless except a strong UV band $(219 \mathrm{~nm})$ assigned to intra-ligand and HS charge transfer bands. The spectral changes observed upon cooling, like isosbestic points or the appearance at $103 \mathrm{~K}$ of two well-resolved bands (at 349, 
$\sim 278 \mathrm{~nm}$ ) assigned to LS metal-to-ligand charge transfer (MLCT) absorptions, ${ }^{29,36}$ prove the SCO process that is complete at room temperature.

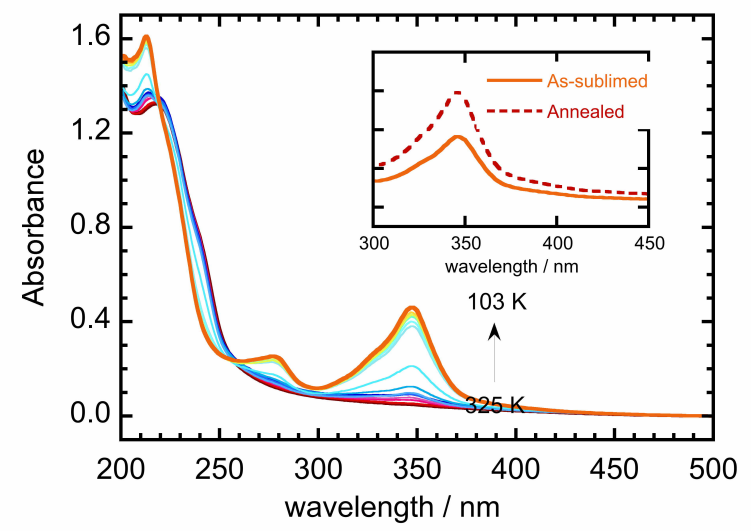

Fig. 4 Absorption spectra recorded upon cooling of the as-sublimed $130 \mathrm{~nm}$-thick layer (1); (inset) superposition of the low-temperature spectra collected before and after annealing of the $130 \mathrm{~nm}$ thick-film.

The SCO curve (Fig. 5) may be extracted by plotting the temperature dependence of the relative area of the MLCT absorption that is proportional to the fraction of HS SCO molecules $\left(\mathrm{x}^{\mathrm{HS}}\right)$. The data show that the layer $\mathbf{1}$ undergoes a first-order spin transition associated with a quite large asymmetric hysteresis loop ( $\mathrm{T} \downarrow \approx 144 \mathrm{~K}, \mathrm{~T} \uparrow \approx 161 \mathrm{~K}$ ) but the spin-state switching is incompleted at low temperature, as analyzed below.

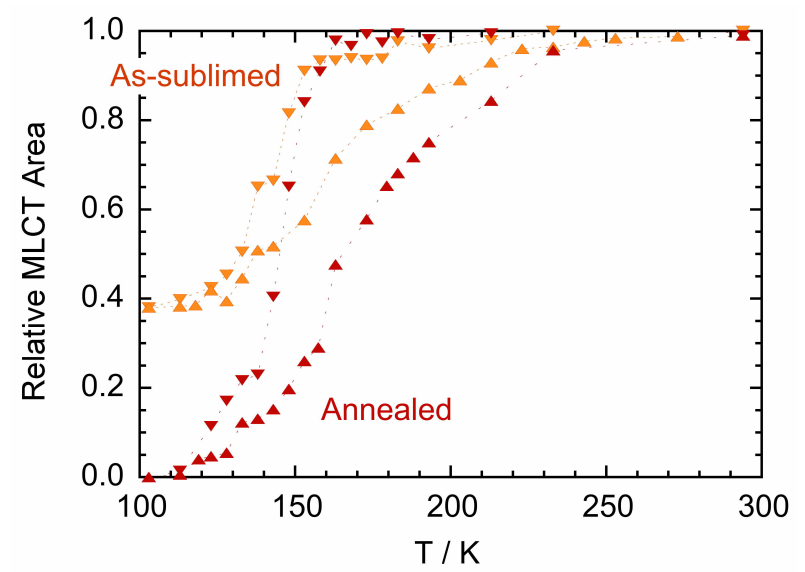

Fig. 5 (a) SCO curve of $\mathbf{1}$ in the as-sublimed $(\boldsymbol{\nabla}, \mathbf{\Delta}))$ and annealed $(\boldsymbol{\nabla}, \mathbf{\Delta})$ form extracted from the temperature dependence of the relative MLCT band area. All the data were normalized with respect to those determined after the layer annealing.

After the ex-situ annealing (Fig. 4), the spectra reproduce the signatures of the compound in the HS and LS state with an enhancement of the absorptions (scaling factor of 1.61 for the LS MLCT band) and some baseline drift. This observation shows a quantitative jump in the proportion of SCO species again assigned to the conversion of HS species into SCO ones, which occurs whatever the film thickness. The characteristics of the spin transition of $\mathbf{1}$ (Fig. 5) are little modified by the sample annealing (the $2 \mathrm{~K}$ raise of $\mathrm{T}_{1 / 2}$ and broadening of the hysteresis being close to the experimental error). To the best of our knowledge, this is the first report of a bistability (centered at ca. $152 \mathrm{~K}, 17 \mathrm{~K}$ hysteresis width) observed in molecule-based layer of this thickness.

The issue of the proportion of HS molecules in the as-sublimed layers should be addressed in relation with its origin. For that, we have measured the absorption changes at $366 \mathrm{~nm}$ between the original and the annealed samples (thickness $\leq 1740 \mathrm{~nm}$ ). The plot (Fig. S15) of $x^{\mathrm{HS}}$ res vs. the layer thickness, including the optical and magnetic data, doesn't reveal systematic deviation as it would be expected in case of the formation of HS structural defects ${ }^{38}$. Therefore, the set of $x^{\text {HS }}$ res values merged at ca. $42(6) \%$ might represent the proportion of the metastable phase, as discussed below.

To summarize, the thin and thick layers present quite robust features: (i) after the sublimation, a mixture of two polymorphs of $\mathrm{Fe}^{\mathrm{II}}\left[\mathrm{HB}\left(3,5-(\mathrm{Me})_{2} \mathrm{Pz}\right)_{3}\right]_{2}$ : the phase undergoing a cooperative first-order spin transition and a new metastable phase, (ii) a quite stable proportion of HS species whatever the film thickness, (iii) after the transformation of the metastable phase by thermal annealing, a complete first-order spin transition and at least for the thickest layers, the widening of the hysteresis loop. It can be noted that in the final stable layer, the $\left(T_{1 / 2}, \Delta T\right)$ characteristics of hysteresis vary from (152 $\mathrm{K}, 19 \mathrm{~K}$ ) to (ca. $\geq 179 \mathrm{~K}, \geq 43 \mathrm{~K}$ ) when the thickness of films increases from 130 (case of 1) to 8020 (case of 2) nm respectively.

\section{Discussion}

\section{Polymorphism and Surface-induced phase}

The formation of two crystalline modifications in the films with different thermodynamical stability can be related to the polymorphism whose importance on the SCO properties is well recognized. ${ }^{39,40}$ Besides, the formation of novel crystal structures may result from the crystallization on a solid surface. ${ }^{41}$ Polymorphism and metastability, characterized with layers of $\mathrm{Fe}^{\mathrm{I}}\left[\mathrm{HB}(\mathrm{Pz})_{3}\right]_{2}{ }^{36}$ or $\mathrm{Fe}{ }^{11}\left[\mathrm{HB}\left(3,5-(\mathrm{Me})_{2} \mathrm{Pz}\right)_{3}\right]_{2}$ (this work) represent from Jones et $a l^{42}$ quite general features of organic materials, when sublimed on surfaces. The observation of the so-called -substrate-induced phase (SIP)- reflects on how the structural form and stability vary with the kinetic and thermodynamical parameters controlling nucleation and growth of ordered molecular arrangements, as well as the interfacial interactions. So the physical vapor deposition of $\mathrm{Fe}^{\prime \prime}\left[\mathrm{HB}\left(3,5-(\mathrm{Me})_{2} \mathrm{Pz}\right)_{3}\right]_{2}$ produces a metastable surface-induced phase, which evolves toward the bulk phase by a thermally activated process. Unexpectedly, we observe in the assublimed layers that, the SIP and the bulk phase coexist in a quite stable proportion whatever the layer thickness, the nanograin size or the ageing time are. It can thus be suggested that the mixing of phases results probably from a parallel crystallization on the substrate and not from a structural interconversion during the layer growth. Among other things, this feature raises the issue of the influence of the substrate on the growth of crystalline arrangements of molecules 
(stabilization of new crystalline phase, proportion of coexisting phases, epitaxial effect) and in fine, the relationship with the growth of a few or a single monolayer. That should be investigated in the future as well as the consequence on the spin-state switching of molecules forming nanocrystals or 2D crystals.

\section{Structure-properties analysis}

The incompleted spin transition of the sublimed samples corresponds to the mixture of a triclinic polymorph exhibiting a first-order spin transition and of a metastable tetragonal polymorph. It seems reasonable to propose that the latter consists in HS molecules at any temperature that are stabilized in an uncrowned environment as justified by the relatively large expansion of the tetragonal unit-cell. However alternative hypotheses should also be considered: a HS contribution resulting from crystal defects in the lattice ${ }^{38}$ or from the nanograin surface ${ }^{9,10}$. We note that in comparison with the bulk, the x-ray reflections do not broaden, the SCO characteristics (cooperativity, hysteresis) do not show significant alteration, and as pointed above, the proportion of HS residue is very consistent in the series contrarily to what would be expected for a loss of crystallinity. The HS species may be favored at the surface of the SCO nanoparticles. ${ }^{10,43}$ The highest value of molecules located at the particle's surface, estimated at $12 \%$ (particle size $=110 \mathrm{~nm}$, aspect ratio $=4$ ) is well below the $42 \%$ averaged ratio of $\mathrm{HS}$ residue determined for the $130 \mathrm{~nm}$-thick film and all the thickest ones. These points discard the hypothesis of a surface effect and thus, we can confidently ascribe this HS response to the metastable tetragonal phase. The proportion of this phase is very likely determined by the experimental conditions adopted for the sublimation.

\section{SCO characteristics and enhancement of bistability}

One noteworthy result is the observation of a spin-transition $\left(T_{1 / 2}=152 \mathrm{~K}\right)$ associated to a $17 \mathrm{~K}$-width hysteresis in a very thin film of a molecule-based material. The bistability, as well as the asymmetrical shape of the hysteresis, witness the persistence of phase transformation accompanying the SCO process. These properties are close to the ones characterized ${ }^{20}$ with a more than four times thicker film $\left(\mathrm{T}_{1 / 2} \sim 150 \mathrm{~K}, \Delta \mathrm{T} \sim \mathrm{ca}\right.$. $21 \mathrm{~K}$ ) of this compound. They should also be compared with those of $\mathrm{Fe}(\text { phen })_{2}(\mathrm{NCS})_{2}$ processed as surfactant-free nanoparticles (dimensions: $142 \times 142 \times 74 \mathrm{~nm}^{3}$ ), with which Gaspar, Real et $a l^{12}$ observed a larger hysteresis $\left(T_{1 / 2} \sim 175 \mathrm{~K}\right.$, $\Delta \mathrm{T}=8 \mathrm{~K})$ than the bulk one $(\Delta \mathrm{T}=1 \mathrm{~K})$.

The spin-state switching produces a change of molecular volume and elastic strains that influence the course of the cooperative process. ${ }^{44}$ One consequence of that is a possible feedback exerted in-between the SCO particles (strain, friction) in close contact within the films. This effect, first suggested by some of us, ${ }^{8}$ is hardly prevented in powders of nanoparticles as it was demonstrated that any particle coating ${ }^{8,20}$ or matrix ${ }^{45}$ may alter the SCO characteristics or promote the opening of a hysteresis. Accordingly it can be pointed out that the as- sublimed layers consist in a mixture of SCO-inactive and SCOactive particles of different stiffness, which likely form loose aggregates because of their dissociation in well-shaped single crystals. As a consequence, the interparticle effects, if any, are expected to be weak. Therefore the spin transition and the bistability properties of $\mathrm{Fe}^{11}\left[\mathrm{HB}\left(3,5-(\mathrm{Me})_{2} \mathrm{Pz}\right)_{3}\right]_{2}$ are especially robust at a scale of one hundredth of nanometers. The enhancement of bistability manifested by the upshift of the transition temperature, the broadening of the thermal hysteresis upon the thermal annealing of the same film possibly result from the increase of crystallinity and plausible mutual effects in-between SCO particles.

\section{Conclusions}

The structure-property relationship of this old SCO prototype has been established thanks to a detailed variabletemperature single-crystal $\mathrm{X}$-ray diffraction analysis combined with calorimetric and magnetic measurements. It shows a sequence of crystallographic phase transitions that accounts for the first-order spin transition with an asymmetrical hysteresis $\left(\mathrm{T}_{1 / 2} \sim 180 \mathrm{~K}, \Delta \mathrm{T} \sim 31 \mathrm{~K}\right)$ in the structural, electronic and magnetic properties.

We have identified a new metastable HS tetragonal polymorph assigned to a surface-induced crystallization process, which coexists in the films with the stable triclinic polymorph exhibiting the first-order spin transition. The conversion of the metastable phase into the stable one that takes place in films upon heating results in a complete SCO with enhanced features and that without noticeable change of thickness.

Importantly, with this investigation of $\mathrm{Fe}^{11}\left[\mathrm{HB}\left(3,5-(\mathrm{Me})_{2} \mathrm{Pz}\right)_{3}\right]_{2}$ we demonstrate the occurrence of a thermal bistability of a $130 \mathrm{~nm}$-thick film that is associated with a quite large hysteresis of $17-19 \mathrm{~K}$ width. To the best of our knowledge, this is an unprecedented result when considering molecule-based materials processed in form of films at nanometric scale. The control of the spin-transition completeness as well as the hysteretic features (both the cooperativity and the temperature) that is achieved here via a relatively low temperature annealing of the molecular films is especially attractive for further development directed towards bistable devices.

\section{Experimental}

\section{Materials and methods}

All manipulations were performed under argon atmosphere using the Schlenk technique or the glovebox.

\section{Samples preparation}

The compound $\mathrm{Fe}^{\mathrm{II}}\left[\mathrm{HB}\left(3,5-(\mathrm{Me})_{2} \mathrm{Pz}\right)_{3}\right]_{2}$ was synthesized as reported $^{20}$ except that the rough solid was redissolved in hot THF, filtered to eliminate $\mathrm{K}^{+} \mathrm{BF}_{4}^{-}$residues, then precipitated as a white polycrystalline solid by THF evaporation under vacuum. Elemental analysis (\%) Calcd (Found) for $\mathrm{C}_{30} \mathrm{H}_{44} \mathrm{~B}_{2} \mathrm{~N}_{12} \mathrm{Fe}: \mathrm{C}, 55.42$ (55.27); H, 6.82 (6.80); N, 25.85 (26.05)\%. IR: v/cm ${ }^{-1} 2512$ s (B-H, HS) (Fig. S8). The powder X-ray 
diffraction pattern compares with that based on the singlecrystal X-ray structure (Fig. S2). The thermal stability and the temperature range for the sublimation were checked by thermogravimetry analysis (Fig. S16).

The thin- or thick-layers formed by deposition on substrates were prepared in a chamber under secondary vacuum $\left(10^{-5}\right.$ mbar, $\left.125^{\circ} \mathrm{C}\right)$ or ultra high vacuum $\left(10^{-8} \mathrm{mbar}, 120-140{ }^{\circ} \mathrm{C}\right)$ (details in the ESI). All the effective thicknesses of the Fepyrazolyl borate films were determined using a KLA- Tencor D120 profilometer $(130 \pm 13 \mathrm{~nm})$ or a Dektak-150 (Brucker) profilometer: $90 \pm 40 \mathrm{~nm} ; 160 \pm 10 \mathrm{~nm}, 840 \pm 60 \mathrm{~nm}, 1740 \pm$ 110; $2660 \pm 90 \mathrm{~nm} ; 3470 \pm 60 \mathrm{~nm} ; 8020 \pm 300 \mathrm{~nm} ; 8460 \pm 230$ $\mathrm{nm}$. For the annealing and phase transformation, we checked that for a pressure larger than $10^{-3}$ mbar, the sublimation temperature $\left(-200^{\circ} \mathrm{C}\right)$ is much higher than the temperature required for annealing $\left(76-100{ }^{\circ} \mathrm{C}\right)$ so that, no displacement of matter can be expected upon this treatment. The thickness value of the annealed $8460 \mathrm{~nm}$-thick layer was found to be preserved within the measurement uncertainty. The layer surfaces probed after heating by AFM still showed large nanotextured areas with some cracks.

\section{Details of the $\mathrm{X}$-ray crystallography studies.}

We probed several single-crystals that showed the unit-cell parameters reported by Oliver et $\mathrm{al}^{30}$ but they shattered by cooling down (Fig. S4). However, it has been possible to characterize with a robust crystal the thermal evolution of the unit-cell (Fig. 1, S7) and in parallel, to solve the X-ray structure first at $100 \mathrm{~K}$ in the LS phase, then upon heating at $240 \mathrm{~K}$, i.e. in the SCO range (Table ST1). The X-ray diffraction patterns at $298 \mathrm{~K}$ (HS phase) were collected with a second single-crystal that again didn't survive to the temperature change.

Single-crystal data collection was performed with a Bruker Kappa VENTURE PHOTON 100 diffractometer with $1 \mu \mathrm{S}$ microfocus graphite-monochromated Mo-K $K_{\alpha}$ radiation $(\lambda=$ $0.71073 \AA$ ) and equipped with a Oxford (series 700) Cryostream cooling device. Crystals were mounted on a Cryoloop (Hampton Research) using Paratone- $N$ as cryoprotectant and then, rapidly frozen at 100 (1) K. The data were corrected for Lorentz polarization, and absorption effects. The structures were solved by direct methods using SHELXS- $97^{46}$ and refined against $F^{2}$ by full-matrix least-squares techniques using SHELXL-2013 with anisotropic displacement parameters for all non-hydrogen atoms. Hydrogen atoms were located on a difference Fourier map and introduced into the calculations as a riding model with isotropic thermal parameters. The calculations were performed by using the Crystal Structure crystallographic software package WINGX. ${ }^{48}$ The crystal data collection and refinement parameters are given in Table ST1 and ST2. CCDC 1558084-1558087 contains the supplementary crystallographic data for this paper. These data can be obtained free of charge from the Cambridge Crystallographic Data Centre via http://www.ccdc.cam.ac.uk/Community/Requestastructure. The RT X-ray diffraction (XRD) patterns of powders (Fig. S2) were recorded using a Philipps Panalytical X'Pert Pro MPD diffractomer at $\mathrm{Cu}-\mathrm{K}_{\alpha}$ radiation equipped with a fast detector within the $5-50^{\circ} 2 \theta$ range. Concerning the thin films, the RT
XRD analysis was carried out (Fig. S11) using an Empyrean (PANALYTICAL) diffractometer equipped with a multichannel PIXcel 2D detector and a Cu- $K_{\alpha} X$-ray source $(\lambda=1.54187 \AA)$. Typically, each pattern was recorded in the $\theta-\theta$ BraggBrentano geometry in the $5-40^{\circ} 2 \theta$ range $\left(0.0066^{\circ}\right.$ for $\left.8 \mathrm{~s}\right)$. The in-situ variable temperature XRD measurements (Fig. S12) were performed using an $X^{\prime}$ pert pro (PANALYTICAL) diffractometer equipped with a multichannel $X^{\prime}$ 'celerator detector and a Co- $K_{\alpha}$ X-ray source $(\lambda=1.79031 \AA)$. Each pattern was recorded in the $\theta-\theta$ Bragg-Brentano geometry in the $10-26^{\circ} 2 \theta$ range $\left(0.0084^{\circ}\right.$ for $\left.40 \mathrm{~s}\right)$ with the same optics as for the measurements at ambient temperature. The high temperature oven chamber is an Anton Paar HTK $1200 \mathrm{~N}$. The rise in temperature was between 26 and $100{ }^{\circ} \mathrm{C}$, with a measurement every $2{ }^{\circ} \mathrm{C}$ and a plateau at this temperature of $12 \mathrm{~min}$ (corresponding to the duration of the measurement). To obtain an inert atmosphere, we used a helium flow.

\section{Characterizations}

Atomic force microscopy measurements (tapping mode topography and phase imaging) were performed using a di Innova AFM Bruker with NanoDrive v8.02 software (Fig. S10). Tapping mode images were acquired using silicon tips from Nanosensors (PPP NCSTR) with a resonance frequency ranging between 76 and $263 \mathrm{kHz}$. Images were processed using WsXM software. $^{49}$

The X-ray Photoelectron Spectroscopy (XPS) analyses were carried out with a ThermoFisher Escalab 250 XI spectrometer using a monochromatic X-ray Al- $\mathrm{K}_{\alpha}$ source (Fig. S9). The analysis zone consisted in a $900 \mu \mathrm{m}$ in diameter spot. The instrument was calibrated in energy with the silver Fermi-level $(0 \mathrm{eV})$ and the $3 \mathrm{~d} 5 / 2$ core level of metallic silver $(368.3 \mathrm{eV})$.

The Differential Scanning Calorimetry (DSC) measurements were performed with a Q-20a TA Instrument using aluminum hermetic pans. Temperature varied between 373 and $113 \mathrm{~K}$ with both cooling and heating rates of $10 \mathrm{Kmin}^{-1}$ (cycles 1 and 2) and $1 \mathrm{Kmin}^{-1}$ (cycle 3). Indium value was used for calibration of $\Delta \mathrm{H}$.

The FT-IR measurements spectra of polycrystalline samples were recorded with a Perkin-Elmer spectrometer (Spectrum 100) while those of thin films (Fig. S8) were obtained at RT with a VERTEX 70 spectrometer (Bruker) (MIRS technique).

The UV-vis spectra of films deposited on quartz were obtained on a CARY 5000 double-beam spectrophotometer. Variabletemperature measurements were done with a Eurolabo variable-temperature cell equipped with a Specac temperature controller while $14 \mathrm{~K}$ spectra were collected with a APD Cryogenics closed-cycle helium cryogenic system including a DMX-1E cryostat and a DE-202 expander.

The magnetic susceptibility data were recorded using a Quantum Design SQUID magnetometer (MPMS5S Model) calibrated against a standard palladium sample. The polycrystalline powder was studied with a $2 \mathrm{Kmin}^{-1}$ scanning rate. In case of thin films, the data were collected with $\mathrm{H}$ $=20000 \mathrm{Oe}$ in the settle mode (almost constant rate of 1.6 $\mathrm{K} \cdot \mathrm{min}^{-1}$ ) to optimize the substrate (quartz) thermalization. The in-situ annealing was achieved by heating the sample at $380 \mathrm{~K}$ 
for one hour. Magnetization vs. $\mathrm{H}$ data were collected for $\mathrm{T}=$ 2, 4 and $6 \mathrm{~K}$ for $\mathrm{H}$ values varying between 0 and $5 \mathrm{~T}$.

\section{Acknowledgements}

The work was supported by the CNRS, the French Ministry of Research, the ANR (ANR-BLANC-12 BS10006, SPIROU project). The authors thank Keitaro Nakatani for allowing us to use the sublimator at ENS Paris-Saclay, P. Viel for his kind assistance in recording IR spectra, J. Forté, R. Saint-Martin for their contribution in Powder X-ray measurements, C. Manquest and S. Suffit for helping with the profilometry measurements.

\section{Notes and references}

‡ Footnotes.

§ $\mathrm{C}_{30} \mathrm{H}_{44} \mathrm{~B}_{2} \mathrm{FeN}_{12}$, Triclinic, $P-1,(\mathrm{~T}=298 \mathrm{~K}), \mathrm{a}=8.8124(3) \AA ⿻$ 10.1928(3) $\AA, c=10.7673(4) \AA, \alpha=116.3380(10)^{\circ}, \beta=$ $85.244(2)^{\circ}, \gamma=100.143(2)^{\circ}, V=853.19(5) \AA^{3}(Z=1) ;(T=240 \mathrm{~K}), a$ $=8.7770(9) \AA, b=10.7908(10) \AA, c=10.9916(17) \AA, \alpha=$ $106.485(7)^{\circ}, \beta=108.711(7)^{\circ}, \gamma=109.714(5)^{\circ}, V=833.7(2) \AA^{3}(Z=$ 1); $(T=100 \mathrm{~K}), a=8.7244(5) \AA, b=10.4918(6) \AA, c=10.8211(6)$ $\AA, \alpha=115.322(2)^{\circ}, \beta=98.499(3)^{\circ}, \gamma=109.477(3)^{\circ}, V=793.58(8)$ $\AA^{3}(Z=1)$.

$\S \S$ The platelet-shaped crystal gave rather poor diffraction data which allowed identification of the complex as drawn in Fig. S13, but did not permit a discussion of the structural details. It crystallizes in the quadratic system, space group P-4 $21 \mathrm{~m}(\mathrm{~T}=253$ K) $a=b=20.668(5) \AA$ and $c=8.603(3) \AA, V=3675 \AA 3(Z=4)$.

1 P. Moriarty, Rep. Prog. Phys., 2001, 64, 297.

2 Spin-Crossover in Transition Metal Compounds, I-III, eds. P. Gütlich and H. A. Goodwin, Springer, Berlin, 2004, vol. 233235; Special issue in: Eur. J. Inorg. Chem., 2013, 5-6; Spincrossover materials: Properties and Applications, ed. M. A. Halcrow, Wiley, Chichester, UK, 2013.

3 A. Bousseksou, G. Molnar, L. Salmon and W. Nicolazzi, Chem. Soc. Rev., 2011, 40, 3313-3335.

4 K. S. Kumar and M. Ruben, Coord. Chem. Rev., 2017, 346, 176-205.

5 (a) E. Coronado, J. R. Galán-Mascarós, M. Monrabal-Capilla, J. García-Martínez, P. Pardo-lbáñez, Adv. Mater., 2007, 19, 1359; (b) T. Forestier, S. Mornet, N. Daro, T. Nishihara, S. I. Mouri, K. Tanaka, O. Fouché, E. Freysz and J.-F. Létard, Chem. Commun., 2008, 4327.

6 (a) J. Larionova, L. Salmon, Y. Guari, A. Tokarev, K. Molvinger, G. Molnar and A. Bousseksou, Angew. Chem. Int. Ed., 2008, 47, 8236; (b) I. Boldog, A. B. Gaspar, V. Martinez, P. PardoIbanez, V. Ksenofontov, A. Bhattacharjee, P. Gütlich and J. A. Real, Angew. Chem. Int. Ed., 2008, 47, 6433; (c) F. Volatron, L. Catala, E. Rivière, A. Gloter, O. Stéphan and T. Mallah, Inorg. Chem., 2008, 47, 6584.

7 A. Tissot, L. Rechignat, A. Bousseksou and M.-L. Boillot, J. Mater. Chem., 2012, 22, 3411.

8 Y. Raza, F. Volatron, S. Moldovan, O. Ersen, V. Huc, C. Martini, F. Brisset, A. Gloter, O. Stephan, A. Bousseksou, L. Catala and T. Mallah, Chem. Commun., 2011, 47, 11501.

9 A. Muraoka, K. Boukheddaden and F. Varret, Phys. Rev. B: Condens. Matter, 2011, 84, 054119.

10 G. Félix, W. Nicolazzi, L. Salmon, G. Molnár, M. Perrier, G. Maurin, J. Larionova, J. Long, Y. Guari and A. Bousseksou, Phys. Rev. Lett., 2013, 110, 235701.
11 G. Félix, M. Mikolasek, H. Peng, W.Nicolazzi, G. Molnar, A. I. Chumakov, L. Salmon and A. Bousseksou, Phys. Rev. B, 2015, 91, 024422.

12 F. J. Valverde-Muñoz, A. B. Gaspar, S. I. Shylin, V. Ksenofontov and J. A. Real, Inorg. Chem., 2015, 54, 79067914.

13 R. M. van der Veen, O. H. Kwon, A. Tissot, A. Hauser and A. H. Zewail, Nat. Chem., 2013, 5, 395.

14 (a) S. Cobo, G. Molnár, J. A. Real, A. Bousseksou, Angew. Chem. Int. Ed., 2006, 45, 5786 ; (b) G. Agusti, S. Cobo, A.B. Gaspar, G. Molnár, N. Ould Moussa, P.A. Szilágyi, V. Pálfi, C. Vieu, M.C. Muñoz, J.A. Real and A. Bousseksou, Chem. Mater., 2008, 20, 6721; (c) C. Bartual-Murgui, A. Akou, L. Salmon, G. Molnár, C. Thibault, J.A. Real and A. Bousseksou, Small, 2011, 7, 3385.

15 M. Cavallini, Phys. Chem. Chem. Phys. 2012, 14, 11867.

16 (a) S. Shi, G. Schmerber, J. Arabski, J.-B. Beaufrand, D. J. Kim, S. Boukari, M. Bowen, N.T. Kemp, N. Viart, G. Rogez and E. Beaurepaire, Appl. Phys. Lett., 2009, 95, 043303; (b) E. C. Ellingsworth, B. Turner and G. Szulczewski, RSC Adv., 2013, 3, 3745-3754.

17 H. Naggert, A. Bannwarth, S. Chemnitz, T. von Hofe, E. Quandt and F. Tuczek, Dalton Trans., 2011, 40, 6364.

18 T. Mahfoud, G. Molnar, S. Cobo, L. Salmon, C. Thibault, C. Vieu, P. Demont and A. Bousseksou, Appl. Phys. Lett., 2011, 99, 053307.

19 T. Palamarciuc, J. C. Oberg, F. El Hallak, C. F. Hirjibehedin, M. Serri, S. Heutz, J.-F. Létard and P. Rosa, J. Mater. Chem., 2012, 22, 9690.

20 V. Davesne, M. Gruber, M. Studniarek, W. H. Doh, S. Zafeiratos, L. Joly, F. Sirotti, M.G. Silly, A. B. Gaspar, J. A. Real, G. Schmerber, M. Bowen, W. Weber, S. Boukari, V. Da Costa, J. Arabski, W. Wulfhekel and E. Beaurepaire, J. Chem. Phys., 2015, 142, 194702.

21 H. Naggert, J. Rudnik, L. Kipgen, M. Bernien, F. Nickel, L. M. Arruda, W. Kuch, C. Nather and F. Tuczek, J. Mater. Chem. C, 2015, 3, 7870.

22 C. Lefter, S. Rat, J.S. Costa, M. D. Manrique-Juarez, C. M. Quintero, L. Salmon, I. Séguy, T. Leichle, L. Nicu, P. Demont, A. Rotaru, G. Molnar and A. Bousseksou, Adv. Mater., 2016, 28, 7508.

23 S. Ossinger, H. Naggert, L. Kipgen, T. Jasper_Toennies, A. Rai, J. Rudnik, F. Nickel, L.M. Arruda, M. Bernien, W. Kuch, R. Berndt and F. Tuczek, J. Phys. Chem. C, 2017, 121, 1210.

24 V. Shalabaeva, S. Rat, M. D. Manrique-Juarez, A.-C. Bas, L. Vendier, L. Salmon, G. Molnar and A. Bousseksou, J. Mater. Chem. C, 2017, DOI: 10.1039/c7tc00999b.

25 A. Hauser, Top. Curr. Chem., 2004, 234, 155-198.

26 K. Bairagi, O. Iasco, A. Bellec, A. Kartsev, D. Li, J. Lagoute, C. Chacon, Y. Girard, S. Rousset, F. Miserque, Y. J. Dappe, A. Smogunov, C. Barreteau, M.-L. Boillot, T. Mallah and V. Repain, Nat. Commun., 2016, 7, 12212.

27 F. Prins, M. Monrabal-Capilla, E. A. Osorio, E. Coronado and H. S. J. van der Zant, Adv. Mater., 2011, 23, 1545

28 V. Meded, A. Bagrets, K. Fink, R. Chandrasekar, M. Ruben, F. Evers, A. Bernand-Mantel, J. S. Seldenthuis, A. Beukman and H. S. J. van der Zant, Phys. Rev. B, 2011 , 83, 245415 ; M. S. Alam, M. Stocker, K. Gieb, P. Müller, M. Haryono, K. Student and A. Grohmann, Angew. Chem. Int. Ed., 2010, 49, 1159 ; T. Miyamachi, M. Gruber, V. Davesne, M. Bowen, S. Boukari, L. Joly, F. Scheurer, G. Rogez, T. K. Yamada, P. Ohresser, E. Beaurepaire and W. Wulfhekel, Nat. Commun., 2012, 3, 938.

29 J. P. Jesson, S. Trofimenko and D. R. Eaton, J. Am. Chem. Soc., 1967, 89, 3148; J. P. Jesson, S. Trofimenko and D. R. Eaton, J. Am. Chem. Soc., 1967, 89, 3158 ; J. P. Jesson, J. F. Weiher and S. Trofimenko, J. Chem. Phys., 1968, 48, 2058.

30 J. D. Oliver, D. F. Mullica, B. B. Hutchinson and W. O. Milligan, Inorg. Chem., 1980, 19, 165. 
31 P. Gütlich, A. Hauser and H. Spiering, Angew. Chem. Int. Ed., 1994, 33, 2024.

32 M. A. Halcrow Chem. Soc. Rev. 2011, 40, 4119-4142.

33 (a) G. L. Long, F. Grandjean and D. L. Reger, Top. Curr. Chem., 2004, 233, 91-122; (b) D.L. Reger, J. D. Elgin, E. A. Foley, M. D. Smith, F. Greanjean and G. L. Long, Inorg. Chem., 2009, 48, 9393.

34 A. P. Grosvenor, B. A. Kobe, M. C. Biesinger and N. S. McIntyre, Surf. Interface Anal., 2004, 36, 1564-1574.

35 L. Li, S.M. Neville, A. R. Craze, J.K. Clegg, N. F. Sciortino, K. S. Athukorala Arachchige, O. Mustonen, C. E. Marjo, C. R. McRae, C. J. Kepert, L. F. Lindoy, J. R. Aldrich-Wright and F. Li, ACS Omega, 2017, 2, 3349-3353.

36 L. Salmon, G. Molnar, S. Cobo, P. Oulié, M. Etienne, T. Mahfoud, P. Demont, A. Eguchi, H. Watanabe, K. Tanaka and A. Bousseksou, New J. Chem., 2009, 33, 1283.

37 Very low temperature magnetization measurements were performed as a function of the magnetic field $(\mathrm{T}=6,4,2 \mathrm{~K}, \mathrm{H}$ $=0-5 \mathrm{~T}$ ). The $\mathrm{M}$ vs $\mathrm{H}$ curves characterizing the $\mathrm{S}=2$ state were satisfyingly fitted with a $\mathrm{g}=2.129$ factor and $\mathrm{a} D=$ $10.06(4) \mathrm{cm}^{-1}$ value of zero field splitting.

38 M. S. Haddad, W. D. Federer, M. W. Lynch and D. N. Hendrickson, Inorg. Chem., 1981, 20, 131.

39 J. Tao, R.-J. Huang and L.-S. Zheng, Chem. Soc. Rev., 2012, 41, 703.

40 D. L. Reger, J. R. Gardinier, M.D. Smith, A. M. Shahin, G. J. Long, L. Rebbouh and F. Grandjean, Inorg. Chem., 2005, 4, 1852-1866.

41 D. Gentili, F. Liscio, N. Demitri, B. Schäfer, F. Borgatti, P. Torelli, B. Gobaut, G. Panaccione, G. Rossi, A. Degli Esposti, M. Gazzano, S. Milita, I. Bergenti, G. Ruani, I. Salitros, M. Ruben and M. Cavallini, Dalton Trans. 2016, 45, 134.

42 A. O. F. Jones, B. Chattopadhyay, Y. H. Geerts and R. Resel, Adv. Funct. Mater., 2016, 26, 2233.

43 M. Mirkolasek, G. Félix, W. Nicolazzi, G. Molnar, L. Salmon and A. Bousseksou, New J. Chem., 2014, 38, 1834.

44 R. Bertoni, M. Lorenc, H. Cailleau, A. Tissot, J. Laisney, M.-L. Boillot, L. Stoleriu, A. Stancu, C. Enachescu and E. Collet, Nat. Mater., 2016, 15, 606.

45 (a) A. Tissot, C. Enachescu and M.-L. Boillot, J. Mater. Chem., 2012, 22, 20451 ; (b) R. Tanasa, J. Laisney, A. Stancu, M.-L. Boillot and C. Enachescu, Appl. Phys. Lett., 2014, 104, 031909.

46 Sheldrick, G. M. SHELXS-97, Program for Crystal Structure Solution, University of Göttingen, Göttingen, Germany, 1997.

47 G. M. Sheldrick, Acta Crystallogr., Sect. A: Found. Crystallogr., 2008, 64, 112-122.

48 Farrugia, L. J. J. Appl. Cryst., 1999, 32, 837-838.

49 I. Horcas et al., Rev. Sci. Instrum., 2007, 78, 013705. 